\title{
Laser Technology to Guide Rainfall to a Particular Region
}

\section{Subramaniam TK*}

Sri Sai Ram Engineering College, West Tambaram, Chennai, Tamil Nadu, India

\begin{abstract}
Rain bearing clouds can be effectively guided to a specific region during monsoon or other seasons so that rainfall shall be equitably distributed without creating drought situations. Lasers sent into the lower troposphere region with intensities sufficient to create a temperature gradient and thereby creating a low pressure area in a specific region can invite rain bearing clouds to a region opposite to where heat is generated by laser effect, so as to bring convective rainfall during a season.
\end{abstract}

Keywords: Equitably; Troposphere; Temperature gradient; Low pressure; Convective rainfall; Laser effect

\section{Introduction to Cloud Formation}

The exercise of trying to guide the rainfall to a particular region is dedicated to all the Indian farmers and all people suffering from severe drought conditions all over the world. Tiny droplets of water coalesce into water molecules of larger nuclei and using the famous Gay-Lussac's law which states that under constant volume conditions, the pressure of a fluid is directly proportional to its temperature. These water molecules condense in to cumulus clouds and forms either into an ice crystal or super-cooled water. By the process of condensation, they form into large droplets of water. In a tropical region such as India, the cloud studies should normally be carried out between 1500 to 5000 feet above the Earth's surface. The temperature of the clouds has to be around 20 to $25^{\circ} \mathrm{C}$ and the density of water droplets is expected to be 20 to 1500 droplets per cubic centimeter. The clouds are interspersed with varying sizes of droplets, from a small size of $6 \mathrm{~mm}$ to as big as 35 $\mathrm{mm}$. Larger the droplet concentration in a unit volume of air, smaller the representation of a big droplet. There can be holes inside the cumulus clouds but it depends on two factors, namely the wind and the downdraft that will influence formation of holes inside a cloud [1].

Congestus clouds can produce moderate to intense rain. The cumulus congested cloud gets its origin from the cumulus mediocris and the cumulus humilis clouds. Air temperature changes with altitude, and a warm condition causes clouds to rise to higher altitudes in order to condense. As the cloud rises higher up in the troposphere region, it could result in swelling and accumulating around a single large area and hence the cumulus cloud ultimately takes the shape of a cauliflower and is now ready to produce showers .Sometimes, these clouds start freezing into ice crystals and forms what is known as 'cumulonimbus' clouds that can produce a 'storm' effect. The period of rain will be around fifteen to twenty minutes and then these clouds dissipate in energy. Langmuir [2] suggested that "the surface tension of water provides a slightly higher pressure on the droplets, raising the vapour pressure". Thus the first stage occurs after the droplets coalesce onto the various nuclei. Sometimes, the increased pressure on the droplets result in condensation of water vapour and hence large droplets are formed and thus the second stage of formation of large droplets takes place.

\section{Laser Guided Rainfall}

The author has suggested the use of a $\mathrm{CO}_{2}$ laser $(\lambda=10.6 \mu \mathrm{m})$ whose power is not dissipated by interaction with any gas.

Molecules and so diffraction will not take place. The beam stays coherent. It will cause a heating effect to the last point where it is focused. So, by heating specific lower regions below the troposphere, one can create a temperature difference and hence a pressure difference, enough to invite these clouds to move towards an opposite region because of high temperature and pressure that are prevalent due to presence of heat caused by $\mathrm{CO}_{2}$ lasers. A test target bursts into flame upon irradiation by a continuous wave $(\mathrm{CW}) \mathrm{CO}_{2}$ Terawatt level laser.

Satellite based monitoring system of cloud formations can be an effective guide to send laser beams in an opposite direction towards the lower troposphere and thereby create convective rainfall into a specific region. Factors like wind speed and moisture have to be taken into account while directing the cloud towards specific region for rainfall. Wind speed depends on the pressure differences between any two points in the troposphere. Greater the difference in pressure, between any two given points, larger will be the wind speed. In troposphere, Rossby waves, which are strong winds, dominate in the upper region and they tend to slow down their speeds in the lower troposphere [3-5].

Since our atmosphere is transparent to infrared laser light emitted by a $\mathrm{CO}_{2}$ laser, it can help in creating a low pressure area over and above the real acts of natural ways of attaining one. The $\mathrm{CO}_{2}$ laser can even attain the power of TW (Terawatt) as evidenced by a carbon-dioxide amplifier at the Brookhaven National Laboratory, USA.

\section{Safety Aspect}

It is to be noted that in order to get the laser beam from the ground towards the troposphere, it is necessary that permission is duly obtained from the Air Traffic Control of any authority, of particular city or town, where the laser beam is to be focused towards the sky, for the safe transit of aero planes or helicopters or trainer aircrafts, private jets etc. During the time of the working of the high power laser through a certain area in the sky, care should be taken not to fly an aircraft of any sort so as to avoid accidents or mishaps. Preferably, the laser beam is to be operated during day time only under strict supervision and

*Corresponding author: Subramaniam TK, Professor, Sri Sai Ram Engineering College, West Tambaram, Chennai, Tamil Nadu, India, Tel: 044 - 2251 2222; E-mail: subramaniam.phy@sairam.edu.in

Received January 03, 2018; Accepted January 25, 2018; Published February 20, 2018

Citation: Subramaniam TK (2018) Laser Technology to Guide Rainfall to a Particular Region. J Laser Opt Photonics 5: 173. doi: 10.4173/2469-410X.1000173

Copyright: (๑) 2018 Subramaniam TK. This is an open-access article distributed under the terms of the Creative Commons Attribution License, which permits unrestricted use, distribution, and reproduction in any medium, provided the original author and source are credited. 
Citation: Subramaniam TK (2018) Laser Technology to Guide Rainfall to a Particular Region. J Laser Opt Photonics 5: 173. doi: 10.4173/2469410X.1000173

Page 2 of 2

following all norms of safety to human beings flying on an aero plane and to the birds on the sky.

\section{Acknowledgement}

The author wishes to acknowledge with thanks the support given by the Principal and the management of Sri Sai Ram Engineering College, Chennai, for encouraging to present a conference paper at the USA and also to publish papers in journals of repute.

\section{References}

1. Warner J (1969) The Micro structure of Cumulus Cloud. Part I. General
Features of the Droplet Spectrum. JAS 26: 1049-1059.

2. Irving L (1948) The Production of Rain by a Chain Reaction in Cumulus Clouds at Temperatures Above Freezing. JMET 5: 175-192.

3. Horvath A, Davies R (2001) Simultaneous retrieval of cloud motion and height from polar-orbiter multiangle measurements. Geophys Res Letters.

4. Harris FS (1984) McGraw-Hill Concise Encyclopedia of Science \& Technology Troposphere. It contains about four-fifths of the mass of the whole atmosphere. Appl Opt 15: 2291.

5. Danielson EW, Levin J, and Abrams E, (2003) Meteorology. McGraw Hill. 